\title{
Correlations of Stream Flow and Climatic Variables for a Large Glacierized Himalayan Basin
}

\author{
Manohar Arora*, Rakesh Kumar, Jatin Malhotra, Naresh Kumar \\ National Institute of Hydrology, Roorkee, India \\ Email: ${ }^{*}$ arora@nih.ernet.in
}

Received 29 August 2014; revised 27 September 2014; accepted 18 October 2014

Copyright (C) 2014 by authors and Scientific Research Publishing Inc.

This work is licensed under the Creative Commons Attribution International License (CC BY). http://creativecommons.org/licenses/by/4.0/ c) (i) Open Access

\begin{abstract}
Streamflow represents the integrated response of a watershed to climatic variables, particularly precipitation and air temperature. In this study, relationships between discharge and hydro meteorological parameters near the snout of Gangotri Glacier were investigated. The auto correlations and multi day influence of temperature and rainfall on discharge can provide valuable information about the Glacier response which can be helpful for estimating discharge in data scarce regions. The data for eight continuous ablation seasons (2000-2007) were used investigating correlations, lag cross correlations and multivariate regression analysis between daily mean discharge, daily mean temperature and daily rainfall, whereas last four years data (2008-2011) was used to simulate the daily discharge from the established relations. Snowmelt discharge varies during the rise in the annual temperature cycle in response to the combination of temperature variation and the amount of water held in the evolving snowpack. The discharge and temperature is highly auto correlated. It was found that discharge of a particular day $\left(Q_{i}\right)$ is well represented by the regression equation having $Q_{i-1}, T_{i}$, and $R_{i}$. Such developed regression equation can be used for computing discharge once its input variables are available. The regression equation developed using the eight year data i.e. $Q_{i}=2.962+1.011 Q_{i-1}-0.422 T_{i}+0.203 R_{i}$ is used for forecasting of discharge. For all the years discharge was computed with high accuracy $\left(R^{2}-0.93\right)$.
\end{abstract}

\section{Keywords}

Gangotri Glacier, Correlations, Hydro Meteorological Variables, Storage Characteristics, Discharge

\section{Introduction}

Identification of the relationships between hydrologic and climatic variables is very important for many hydro-

*Corresponding author.

How to cite this paper: Arora, M., Kumar, R., Malhotra, J. and Kumar, N. (2014) Correlations of Stream Flow and Climatic Variables for a Large Glacierized Himalayan Basin. Journal of Water Resource and Protection, 6, 1326-1334.

http://dx.doi.org/10.4236/jwarp.2014.614122 
logic applications such as prediction of missing records, analysis of climate change impacts, and estimation of hydrologic responses of ungauged basins. Statistical approaches have long been used in analyzing the relationships between hydrologic and climatic systems. A standard approach for finding the relationships between hydrologic and climatic variables is to compute pair-wise correlations between time series of hydrologic and climatic variables. Depending on the value of the correlation coefficients, this approach can help identify the strengths of the relationships between variables.

Precipitation-stream flow and precipitation-air temperature relationships are probably the most commonly investigated relationships. Cayan et al. [1] investigated the effects of precipitation, temperature, and snow water content on stream flow. The sensitivity of stream flow to precipitation and temperature changes was investigated by [2]. Kletti and Stefan [3] examined the correlations between stream flow and precipitation, air temperature, wind speed, and dew point temperature. Chowdhury and Ward [4] have quantified the rainfall-runoff relation in the greater GBM basin and identified the possibilities of month-to-seasonal (1 - 3 months in advance) streamflow forecast (especially in the Ganges basin) by employing a simple correlation if rainfall data from countries further upstream are available on a real-time and continuous basis. Hodgkins et al. [5] investigated to understand the relations between winter climatic variables and April streamflows. They found that higher winter (December through March) precipitation is associated with higher April streamflows at many gages in northern and central New England. This implies that snowpack accumulation is an important mechanism for winter water storage and subsequently important for spring streamflows in this area. Higher March air temperatures are associated with lower April streamflows at many gages in central and southern New England, likely because the majority of snowmelt runoff occurs before April in warm years. Pal et al. [6] analyzed the variability of MAM (MarchApril-May) and JJAS (June-July-August-September) seasonal Satluj River flow into the Bhakra dam in India through Pearson anomaly correlation and composite analyses with antecedent and concurrent seasonal climatic and atmospheric circulation patterns.

Previous studies showed that although precipitation and air temperature are the two most important parameters affecting stream flow, some other climatic variables can also have major impacts. In glacierized basins the streamflow is dependent on the lag due to travel time and melt water storage characteristics. In this study, we included precipitation and temperature lags relationships between stream flow and climatic conditions. The data were collected by establishing a discharge site and meteorological observatory.

\section{Study Area}

The present study was carried out for the Gangotri Glacier, which is one of the largest glaciers of Himalayas. This glacier is located in the Uttarkashi District of Uttarakhand State (UA) falling in the Garhwal Himalayan region. The location of Gangotri Glacier is shown in Figure 1. The study area lies within the latitudes $30^{\circ} 43^{\prime} \mathrm{N}$ $30^{\circ} 01^{\prime} \mathrm{N}$ and longitudes $79^{\circ} 0^{\prime} \mathrm{E}-79^{\circ} 17^{\prime} \mathrm{E}$. The proglacial melt water stream, known as Bhagirathi River, emerges

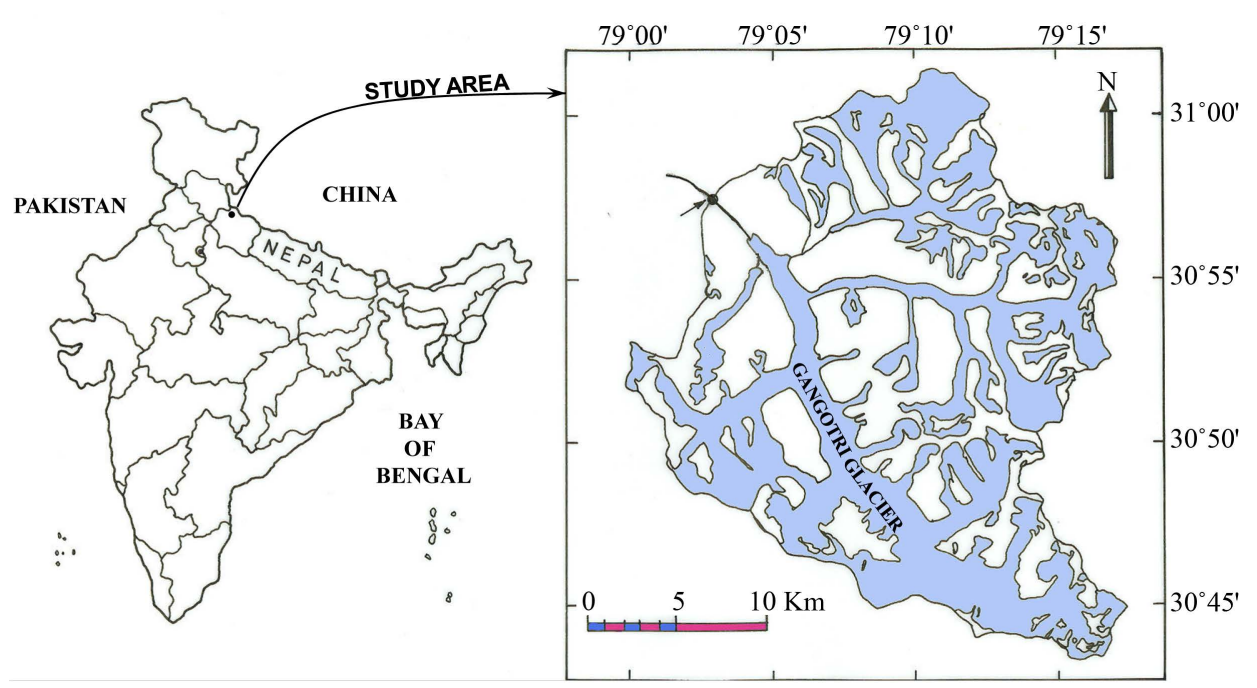

Figure 1. Location and basin map of the Gangotri Glacier in the Garhwal Himalayas. 
out from the snout of the Gangotri Glacier at an elevation of $4000 \mathrm{~m}$. The approach to the snout of the Glacier includes a trekking of about $18 \mathrm{~km}$ distance starting from the Gangotri town. The major part of the trekking is along the Bhagirathi River. A meteorological observatory and discharge site were established and data were collected for the entire ablation period.

\section{Methodology and Data Used}

The climate variability affects the streamflow of a glacierized basin. We calculated the correlation coefficients between stream flow and climatic variables. Basically regression analysis was performed and 1) Discharge auto-correlation; 2) discharge-temperature correlation and 3) discharge rainfall correlation were determined for different lag periods ( 0 - 3 days). Multivariate regression between discharge, temperature and rainfall was also performed.

As data collection was one of the major tasks for this study. We had continuous monitoring of hydro meteorological variables for about 12 years. In the present analysis, as such hydro-meteorological data of 12 years (2000-2011) have been used. The first 8 years data (2000-2007) were used for determining correlations, lagcross-correlations and multivariate regression analyses between daily mean years discharge, daily mean temperature and daily rainfall. The last 4 years data (2008-2011) were used to estimate the discharge using established relationship. The time series for different variables (discharge, temperature and rainfall) were prepared as a function of time-lag of 0 - 3 days for each ablation seasons of 8 years (2000-2007). A combined series of these 8 ablation seasons was prepared by considering all ablation seasons together in chronological order and used in the analysis for developing generalized relationship.

\section{Correlation of Discharge with Predictors}

\subsection{Discharge Auto-Correlation}

The Discharge auto-correlations is determined to examine if there exist a cross correlation between past and future values of discharge. Figure 2 depicts the discharge auto-correlation for different melt seasons as well as for the combined series of 8 seasons (2000-2007). The values of discharge auto-correlation for different ablation seasons are given in Table 1. A comparison of discharge auto-correlations for different years indicates that discharge auto-correlation is very high for all the years. The distribution of discharge auto-correlation with time-lag for different years shows a reduction in auto-correlation with increase in time-lag. It is found that discharge auto-correlation varied from 0.98 - 0.81 for the time-lag from 1 - 3 days. The corresponding values of discharge auto-correlation for the combined discharge series varied from $0.97-0.88$. Such reduction in discharge auto-correlation may be due to combined effect of melting conditions of glacier, precipitation pattern and water storage and drainage characteristics within the basin. It is observed that although a good auto correlation exists

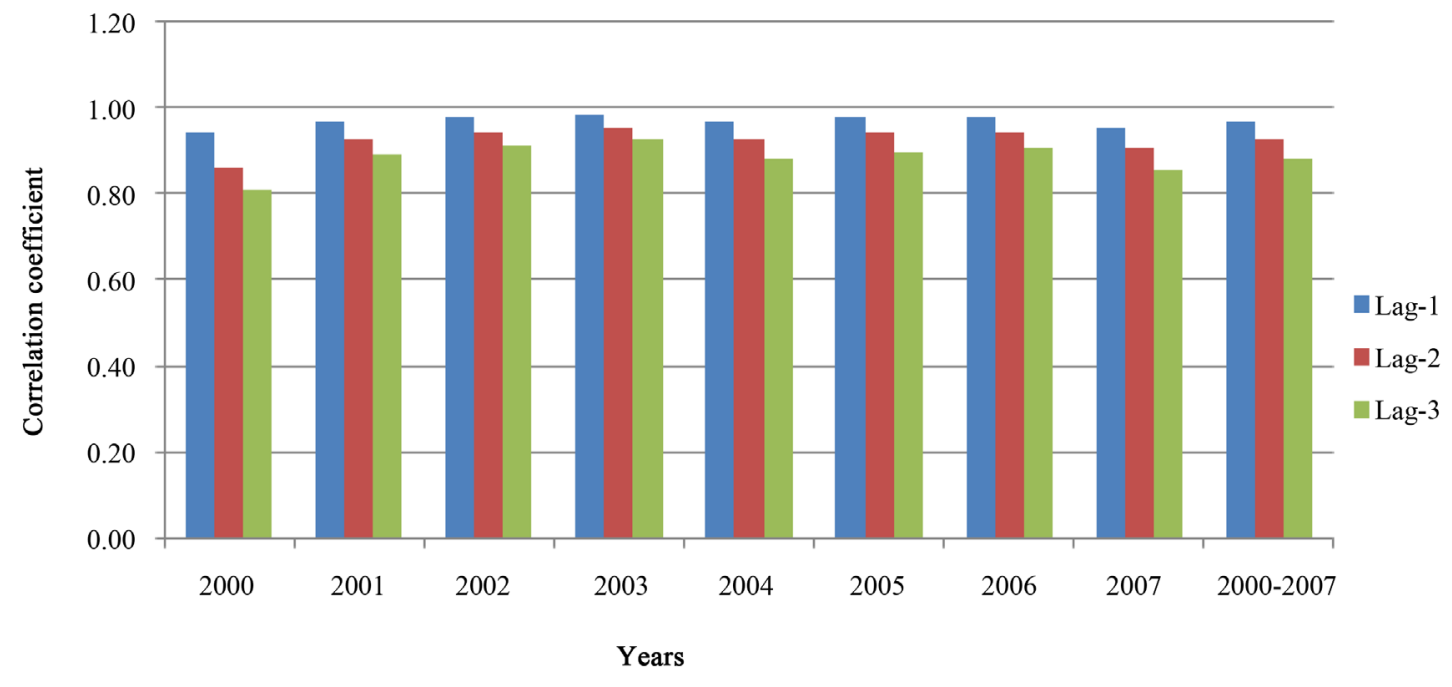

Figure 2. Multiple day influence (1 - 3 days) on discharge auto-correlations for the Gangotri Glacier streamflow. 
Table 1. Multiple day influence (1 - 3 days) on discharge auto-correlations for the Gangotri Glacier streamflow.

\begin{tabular}{cccc}
\hline & \multicolumn{2}{c}{ Discharge auto-correlation } & Lag 3 \\
Year & Lag 1 & Lag 2 & 0.81 \\
2000 & 0.94 & 0.86 & 0.89 \\
2001 & 0.97 & 0.93 & 0.91 \\
2002 & 0.98 & 0.95 & 0.93 \\
2003 & 0.98 & 0.95 & 0.88 \\
2004 & 0.97 & 0.93 & 0.90 \\
2005 & 0.98 & 0.94 & 0.91 \\
2006 & 0.98 & 0.94 & 0.86 \\
2007 & 0.95 & 0.91 & 0.88 \\
\hline
\end{tabular}

for all considered time-lags, the maximum auto-correlation is found with the previous day's discharge (0.98 0.94). This high discharge autocorrelation indicates the dominance of strong storage characteristics in the response of runoff from the glacierized basin. The results show that discharge for a particular day is very much dependent on the previous day's discharge. It means that if previous days discharge is known then the forecasting of next day discharge can be easier. It is likely that the dominance of delaying characteristics of the glacier and little contribution from rainfall to the streamflow. In the present study basin has provided higher discharge auto-correlations.

\subsection{Discharge-Temperature Correlation}

The simple correlation coefficients for temperature, given for lags of up t o $3 \mathrm{~d}$ and taken as a function of time, indicate about the "mean" delay in melt-water runoff. The lag of the correlation maximum should represent a "mean" transit time of all melt water being recorded at the gauging station. Correlations established between discharge and air temperatures with a time-lag of temperature from $0-3$ days $\left(T_{i}, T_{i-1}, T_{i-2}\right.$ and $\left.T_{i-3}\right)$ are shown in Figure 3. The values of discharge-temperature correlation for each ablation season and combined data series are given in Table 2. The analysis shows that discharge is well correlated with temperature for each ablation season. It is found that for all the years' discharge-temperature correlation decreased with increase in time-lag. The value of discharge correlation varied from 0.82 - 0.42 for a time-lag from 0 - 3 days. The highest correlation between discharge and temperature was obtained with temperature of 0-day time lag. In other words, discharge of a particular day has shown highest correlation (0.82) with temperature of the same day. The combined series of discharge and temperature also show a good correlation $(0.66-0.51)$ with temperature having time-lag from 0 3 days. As such a good correlation has been found between discharge $\left(Q_{i}\right)$ and temperature $\left(T_{i}, T_{i-1}, T_{i-2}\right.$ and $\left.T_{i-3}\right)$ for all the years, showing important role of temperature in producing runoff in the glacierized basin.

\subsection{Discharge-Rainfall Correlation}

The correlations between discharge and rainfall with time-lags between 0 and 3 days $\left(\mathrm{R}_{\mathrm{i}}, \mathrm{R}_{\mathrm{i}-1}, \mathrm{R}_{\mathrm{i}-2}, \mathrm{R}_{\mathrm{i}-3}\right)$ for different ablation seasons were developed. The values of discharge and rain correlations for each ablation season and combined data series are given in Table 3 and presented in Figure 4. For the study basin, the correlation between discharge and rainfall are found poor and highly variable for all the years. No consistent change in correlation between discharge and rainfall was found with increase in time-lag. Correlations between discharge and precipitation are expected to be weak at the start of the season in comparison to later half of the season. In later half of the season, the response of streamflow to rainfall becomes faster compared with other months because of changes in the physical conditions of the glacier. During this time, the glacier ice surface is exposed to a large extent. The response to rainfall is always faster from an ice covered surface compared with a snow covered one: rain falling on a snow-covered surface is first absorbed by the snowpack and later released to the streamflow, whereas the ice surface is impervious. Hence, rain contributes to the runoff at the outlet in a relatively shorter time period. However, sometimes intense rainstorms found in this region at the beginning of the rain season 


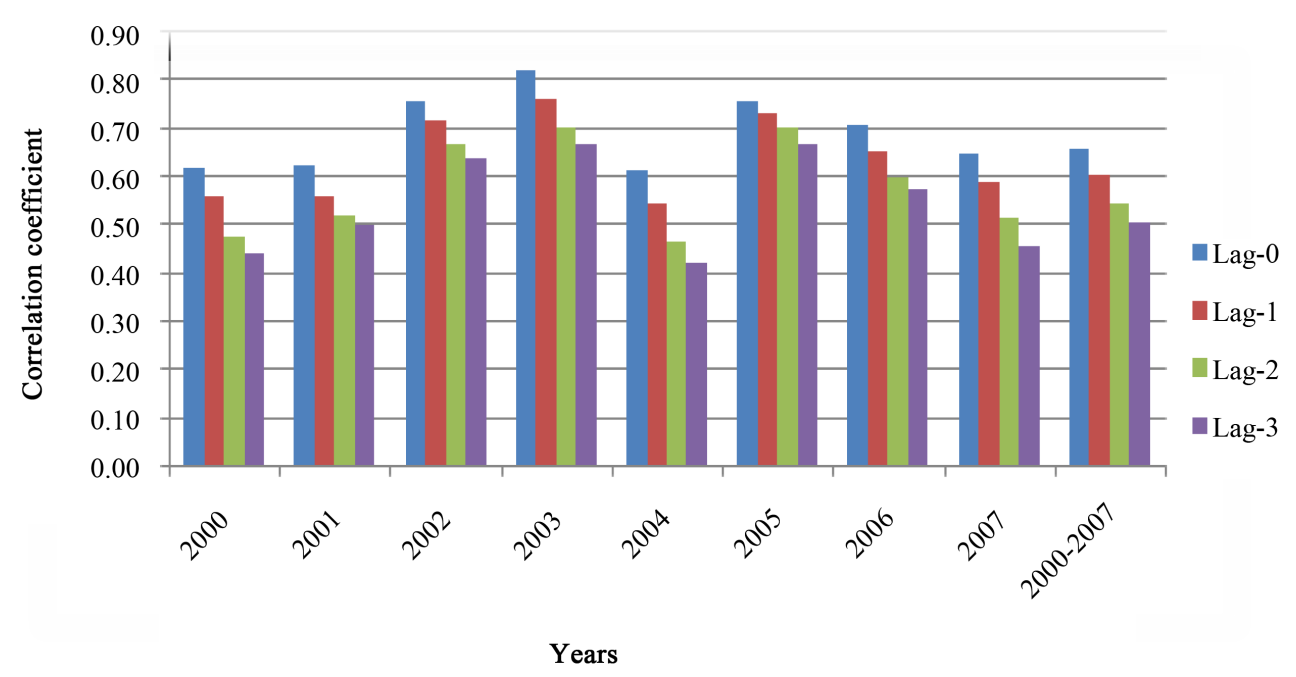

Figure 3. Multilple day influence (0 - 3 days) on discharge temperature correlations for the Gangotri Glacier streamflow.

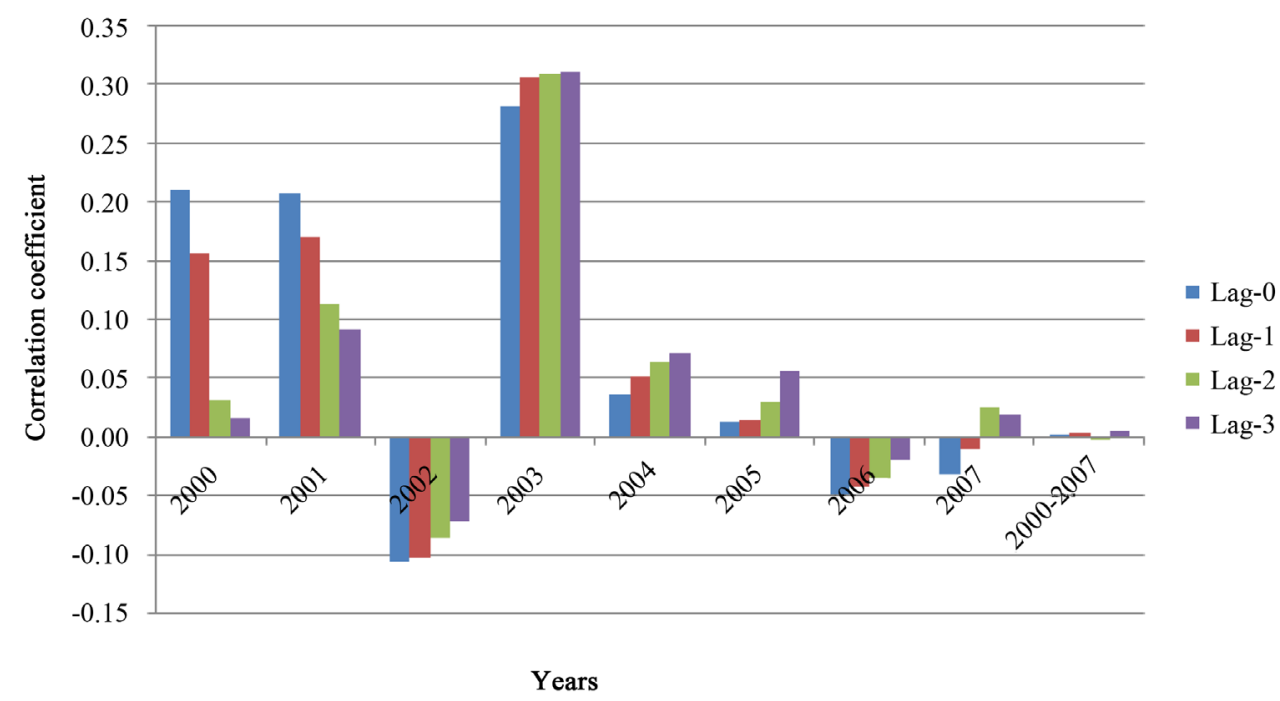

Figure 4. Multiple day influence (0 - 3 days) on discharge rainfall correlations for the Gangotri Glacier streamflow.

Table 2. Multiple day influence (0 - 3 days) on discharge temperature correlations for Gangotri Glacier streamflow.

\begin{tabular}{ccccc|}
\hline & \multicolumn{2}{c}{ Discharge-temperature correlation } \\
\hline Year & Lag 0 & Lag 1 & Lag 2 3 \\
\hline 2000 & 0.62 & 0.56 & 0.48 & 0.44 \\
2001 & 0.63 & 0.56 & 0.52 & 0.50 \\
2002 & 0.76 & 0.72 & 0.67 & 0.64 \\
2003 & 0.82 & 0.76 & 0.70 & 0.67 \\
2004 & 0.61 & 0.54 & 0.47 & 0.42 \\
2005 & 0.76 & 0.73 & 0.71 & 0.67 \\
2006 & 0.71 & 0.66 & 0.60 & 0.58 \\
2007 & 0.65 & 0.59 & 0.52 & 0.46 \\
$2000-2007$ & 0.66 & 0.60 & 0.55 & 0.51 \\
\hline
\end{tabular}


Table 3. Multiple day influence (0 - 3 days) on discharge rainfall correlations for the Gangotri Glacier streamflow.

\begin{tabular}{ccccc|}
\hline & \multicolumn{2}{c}{ Discharge-rain auto-correlation } \\
\hline Year & Lag 0 & Lag 1 & Lag 2 & Lag 3 \\
\hline 2000 & 0.21 & 0.16 & 0.03 & 0.02 \\
2001 & 0.21 & 0.17 & 0.11 & 0.09 \\
2002 & -0.11 & -0.10 & -0.09 & -0.07 \\
2003 & 0.28 & 0.31 & 0.31 & 0.31 \\
2004 & 0.04 & 0.05 & 0.06 & 0.07 \\
2005 & 0.01 & 0.02 & 0.03 & 0.06 \\
2006 & -0.05 & -0.04 & -0.03 & -0.02 \\
2007 & -0.03 & -0.01 & 0.03 & 0.02 \\
$2000-2007$ & 0.003 & 0.004 & -0.002 & 0.007 \\
\hline
\end{tabular}

typically produced runoff immediately after a large storm. In general, discharge was positively correlated with rainfall, except years 2002, 2006 and 2007. A negative correlation is possible when rainfall occurs near the snout and low temperature conditions prevail. Such weather conditions allow for snowfall over the major part of glacier, which ceases the melting of glacier and in turn reduces discharge.

\section{Regression Relationship and Its Use for Estimation of Streamflow}

It is well established that energy input exerts a strong direct influence on discharge. Both form and timing of precipitation will have considerable influence on runoff. To establish the relations between discharge and meteorological elements, for instance, as a basic study for the purpose of forecasting discharge of a glacier river, regressive schemes for the time series were employed. Multiple regression equations relating total annual discharge to mean summer air temperature and precipitation variables provide a high degree of explanation in basins with higher proportions of ice cover. To estimate daily streamflow from the Gangotri Glacier basin, multiple regression equations were developed separately for each melting season (2000-2007) and the combined series of 8 melt seasons. Stepwise regression technique has been used to identify important variables for estimating the discharge of Gangotri Glacier basin. The regression equations were developed considering the possible climatic factors, which may significantly influence the runoff. Discharge from the basin was used as the dependent variable and 11 independent variables namely $Q_{i-1}, Q_{i-2}, Q_{i-3}, T_{i}, T_{i-1}, T_{i-2}, T_{i-3}$ and $R_{i}, R_{i-1}, R_{i-2}, R_{i-3}$ respectively, were used as independent variables.

The resulting multiple regression equations obtained through stepwise regression and corresponding values of correlation for each year and for the combined series of all 8 seasons is given in Table 4. It can be noted that some of the variables were dropped in the regression equations due to their statistical insignificance determined by stepwise regression approach. Goodness of fit of multiple regression equations is high even though mean air temperature is probably a poor substitute for radiation measurements, and precipitation records are for stations outside catchment boundaries and at relatively low elevations. A high value of $\mathrm{R}^{2}$ varied between 0.90 and 0.99 for all the eight (8) ablation seasons, showing that discharge data are well represented by these equations. For the combined series also a very high value of $\mathrm{R}^{2}(0.99)$ was obtained.

The regression equations developed were used to estimate daily streamflow for four independent years (2008 to 2011). The estimation of discharge was made using generalized regression equation developed from combined data series of 8 ablation seasons. A comparison of computed and observed daily streamflow for 2008 to 2011 is given in Figure 5. Figure 6 shows that computed value of discharge is very close to matched with estimated values of the models during the years 2008 to 2011.

\section{Conclusions}

It is important to understand the sensitivity of streamflow to climatic variation because people and aquatic ecosystems are dependent upon a water supply that is adequate, particularly in summer low-flow seasons. The 
Table 4. Regression equations developed for the Gangotri Glacier basin using stepwise regression approach (2000-2007) and combined series.

\begin{tabular}{clc}
\hline Year & \multicolumn{1}{c}{ Multiple regress on equat $_{\mathrm{i}}$ ons } & $\mathrm{R} 2$ \\
2000 & $\mathrm{Q}_{\mathrm{i}}=-5.975+0.869 \mathrm{Q}_{\mathrm{i}-1}+1.489 \mathrm{~T}_{\mathrm{i}}+0.565 \mathrm{R}_{\mathrm{i}}$ & 0.90 \\
2001 & $\mathrm{Q}_{\mathrm{i}}=6.491+0.992 \mathrm{Q}_{\mathrm{i}-1}-0.679 \mathrm{~T}_{\mathrm{i}}+0.962 \mathrm{R}_{\mathrm{i}}$ & 0.94 \\
2002 & $\mathrm{Q}_{\mathrm{i}}=-2.382+0.951 \mathrm{Q}_{\mathrm{i}-1}+0.606 \mathrm{~T}_{\mathrm{i}}+0.128 \mathrm{R}_{\mathrm{i}}$ & 0.96 \\
2003 & $\mathrm{Q}_{\mathrm{i}}=0.228+0.966 \mathrm{Q}_{\mathrm{i}-1}+0.124 \mathrm{~T}_{\mathrm{i}}+0.977 \mathrm{R}_{\mathrm{i}}$ & 0.97 \\
2004 & $\mathrm{Q}_{\mathrm{i}}=3.498+0.987 \mathrm{Q}_{\mathrm{i}-1}-0.312 \mathrm{~T}_{\mathrm{i}}+0.375 \mathrm{R}_{\mathrm{i}}$ & 0.94 \\
2005 & $\mathrm{Q}_{\mathrm{i}}=-4.808+0.941 \mathrm{Q}_{\mathrm{i}-1}+0.942 \mathrm{~T}_{\mathrm{i}}+0.289 \mathrm{R}_{\mathrm{i}}$ & 0.96 \\
2006 & $\mathrm{Q}_{\mathrm{i}}=0.709+0.965 \mathrm{Q}_{\mathrm{i}-1}+0.103 \mathrm{~T}_{\mathrm{i}}+0.452 \mathrm{R}_{\mathrm{i}}$ & 0.96 \\
2007 & $\mathrm{Q}_{\mathrm{i}}=-2.214+0.926 \mathrm{Q}_{\mathrm{i}-1}+0.583 \mathrm{~T}_{\mathrm{i}}+0.241 \mathrm{R}_{\mathrm{i}}$ & 0.91 \\
$2000-2007$ & $\mathrm{Q}_{\mathrm{i}}=2.962+1.011 \mathrm{Q}_{\mathrm{i}-1}-0.422 \mathrm{~T}_{\mathrm{i}}+0.203 \mathrm{R}_{\mathrm{iI}}$ & 0.99 \\
\hline
\end{tabular}
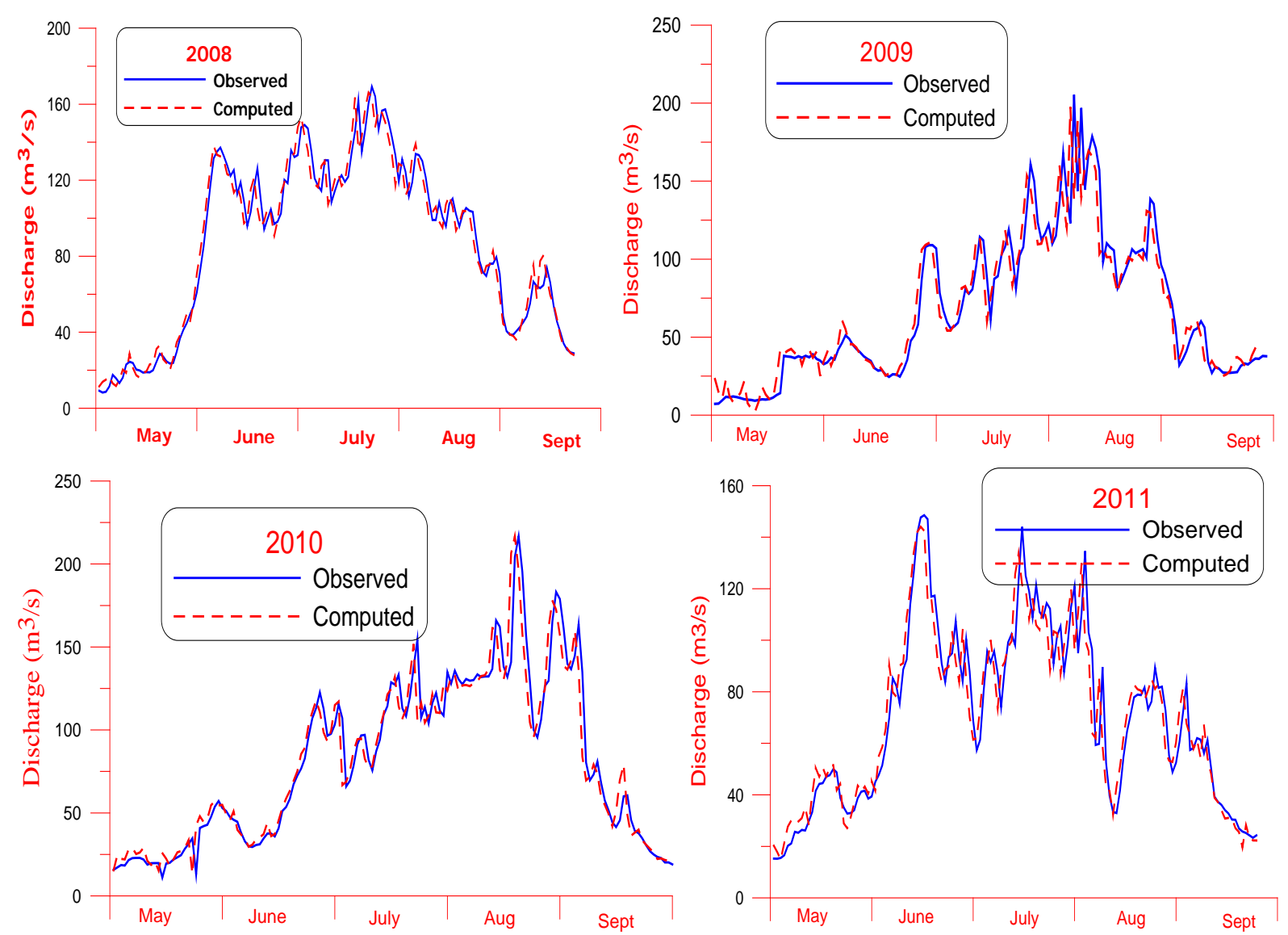

Figure 5. Observed and computed discharge at near the snout of Gangotri Glacier during the year 2008, 2009, 2010 and 2011.

linkages between hydrologic and climatic data are based on complex physical processes that are difficult to conceptualize. In this study, an attempt was made to elucidate some of the characteristics of multi day influence between discharge and meteorological elements which occur in the course of an ablation season. We investigated the relationships between stream flow of Gangotri Glacier and lags in rainfall and temperatures in the basin. The discharge auto correlation provides valuable information about the storage characteristics and Glacier response. The seasonal distribution of discharge auto-correlation suggests that, although a good auto-correlation 

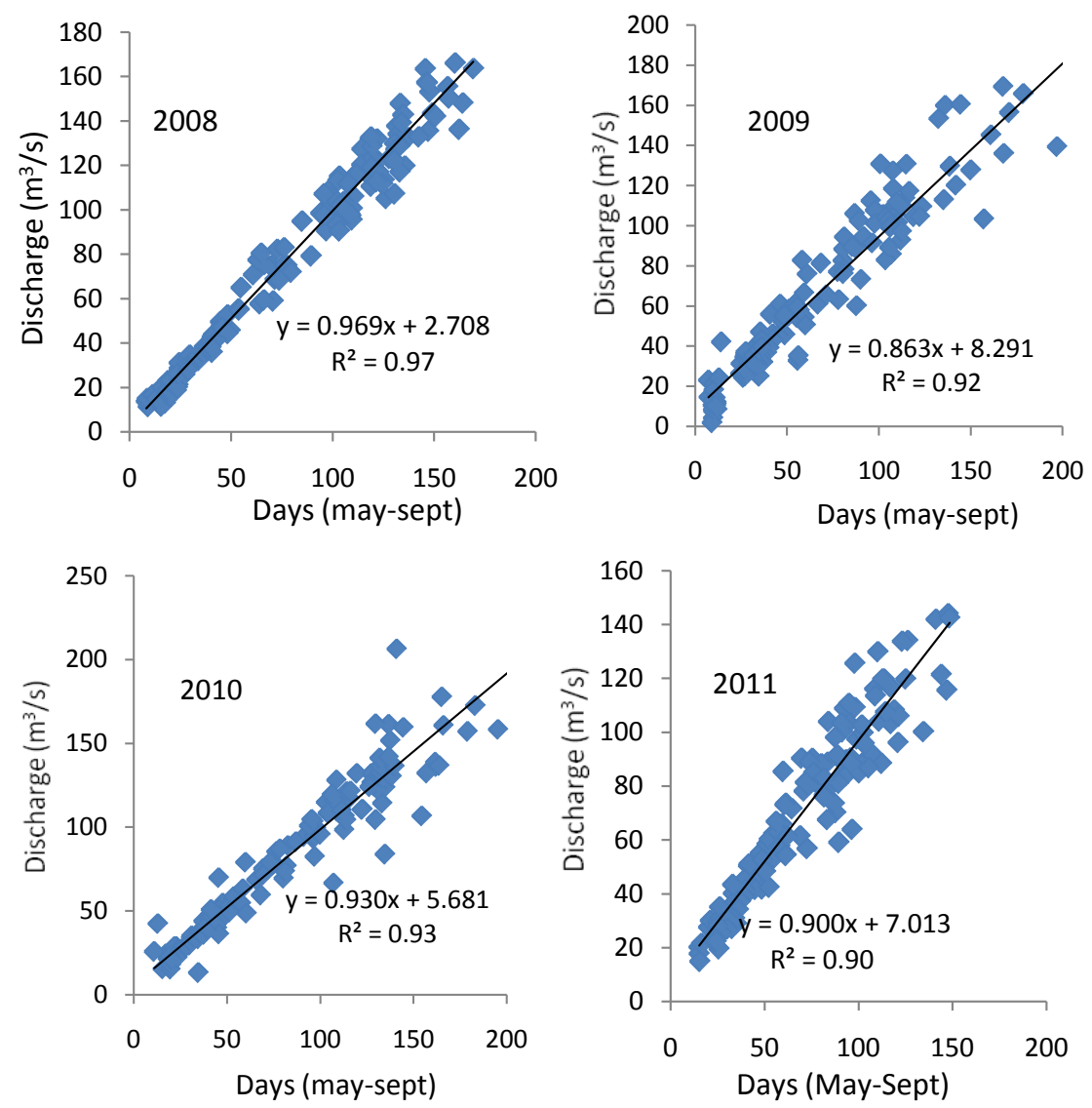

Figure 6. Correlation between observed and estimated discharge at Gangotri Glacier during 2008, 2009, 2010 and 2011.

exists for all the considered time lags, maximum auto-correlation $(0.94-0.98)$ is observed with the previous day's discharge $\left(\mathrm{Q}_{\mathrm{i}-1}\right)$ and for the combined series as well (0.97). It suggests that discharge for a particular day is highly dependent on the previous day's discharge. Therefore, for estimation/forecasting of discharge from the glacierised basin for a particular day, the previous day's discharge becomes a significant predictor. The high discharge auto-correlation indicates the dominance of storage characteristics on the response of runoff from the glacierized basin. Discharge auto-correlation decreases with an increase in the lag period of discharge.

As such the discharge and temperature with time lag from 0 - 3 days were found to be reasonably well correlated. The highest correlation was found with same day temperature, which varied from 0.61 to 0.82 for different years. For the combined series the highest correlation between discharge and same day temperature was 0.66. Like discharge auto correlation, correlation between discharge and temperature also decreased with increase in lag in temperature. Poor and inconsistent correlation was found between discharge and rainfall for all the years.

Multiple linear regression equations developed for the Gangotri Glacier basin separately for each year and for the combined series of 8 years. Stepwise regression approach was used to identify the statistically significant parameters for computing discharge from the basin. It was found that discharge of a particular day $\left(\mathrm{Q}_{\mathrm{i}}\right)$ is well represented by the regression equation having $\mathrm{Q}_{\mathrm{i}-1}, \mathrm{~T}_{\mathrm{i}}, \mathrm{T}_{\mathrm{i}-1}, \mathrm{~T}_{\mathrm{i}-2}$ and $\mathrm{R}_{\mathrm{i}}$. The aim was not exactly to find a model, but to observe the simple correlations between the discharges and the meteorological variables (precipitation $\mathrm{P}$, temperature $\mathrm{T}$, with a 0 to 3 days lag). The established equation using combined series was used to compute discharge for 4 independent years (2008 to 2011). For all the years discharge was computed with high accuracy $\left(\mathrm{R}^{2}-0.93\right)$. The results show that the developed regression equation can be used for computing discharge once its input variables are available.

\section{Acknowledgements}

The author is thankful to Director, National Institute of Hydrology, Roorkee for the support to carry out hydro 
meteorological investigation at Gangotri Glacier.

\section{References}

[1] Cayan, D.R., Riddle, L.G. and Aguado, E. (1993) The Influence of Precipitation and Temperature on Seasonal Streamflow in California. Water Resources Research, 29, 1127-1140. http://dx.doi.org/10.1029/92WR02802

[2] Duell, L.F.W.J. (1995) The Sensitivity of Northern Sierra Nevada Streamflow to Climate Change. Water Resources Bullettin, 30, 841-859. http://dx.doi.org/10.1111/j.1752-1688.1994.tb03333.x

[3] Kletti, L.L. and Stefan, H.G. (1997) Correlations of Climate and Streamflow in Three Minnesota Streams. Climatic Change, 37, 575-600. http://dx.doi.org/10.1023/A:1005396601785

[4] Chawdhury, R.M. and Ward, N. (2004) Hydro-Meteorological Variability in the Greater Ganga-Brahmaputra and Meghna Basins. International Journal of Climatology, 24, 1495-1508. http://dx.doi.org/10.1002/joc.1076

[5] Hodgkins, G.A., Dudley, R.W. and Schalk, L.F. (2012) Relations between Winter Climatic Variables and April Streamflows in New England and Implications for Summer Streamflows. USGS Report, 19.

[6] Pal, I., Lall, U., Robertson, A.W., Cane, M.A. and Bansal, R. (2013) Diagnostics of Western Himalayan Satluj River flow: Warm season (MAM/JJAS) inflow into Bhakra dam in India. Journal of Hydrology, 478, 132-147. 
Scientific Research Publishing (SCIRP) is one of the largest Open Access journal publishers. It is currently publishing more than 200 open access, online, peer-reviewed journals covering a wide range of academic disciplines. SCIRP serves the worldwide academic communities and contributes to the progress and application of science with its publication.

Other selected journals from SCIRP are listed as below. Submit your manuscript to us via either submit@scirp.org or Online Submission Portal.
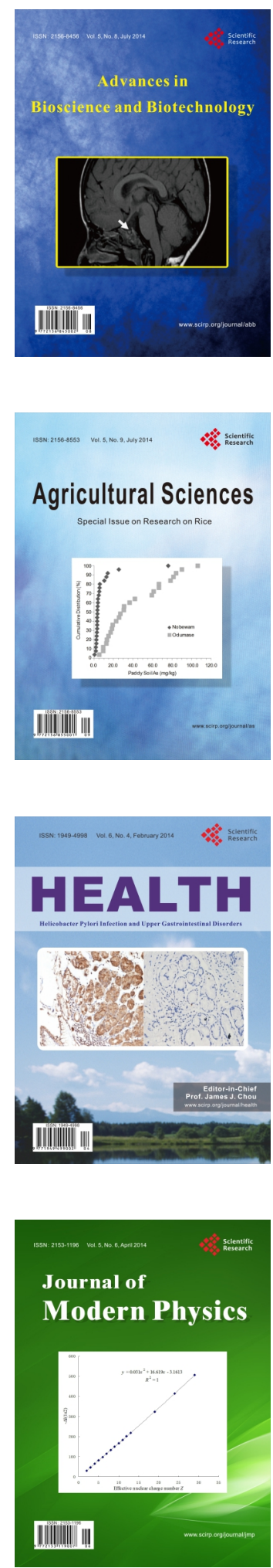
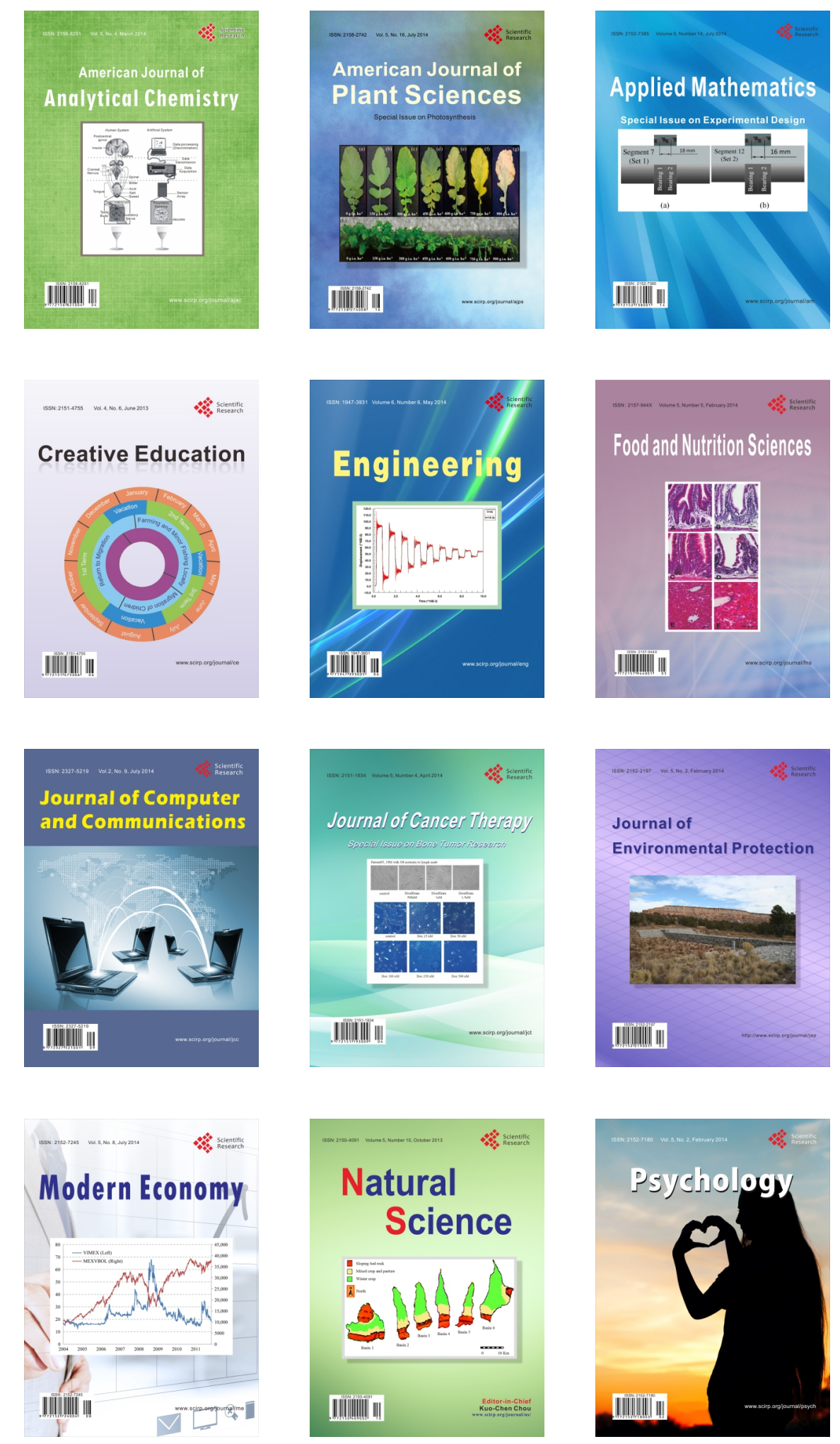